\title{
A Critical Review of 100 Cases of Hysterectomy: A Prospective Study in a Tertiary Care Centre
}

\author{
Dr. Most Fatima Dolon ${ }^{1 *}$, Dr. Rifat Sultana ${ }^{2}$, Dr. Khadiza Rubab ${ }^{3}$, Dr. Nabid Shahriarr ${ }^{4}$, Dr. Afrin Billah ${ }^{5}$, Dr. Mahmuda \\ Naher $^{6}$ \\ ${ }^{1}$ Senior Consultant, Department of Obstetrics and Gynaecology, Shaheed Tajuddin Ahmad Medical College Hospital, Gazipur, Bangladesh \\ ${ }^{2}$ Diploma in Course Gynaecology \& Obstetrics of Bangabandhu Sheikh Mujib Medical University, Dhaka, Bangladesh \\ ${ }^{3}$ Diploma in Course Anaesthesiology of Bangabandhu Sheikh Mujib Medical University Hospital, Dhaks, Bangladesh \\ ${ }^{4}$ Assistant Professor, Department of Obstetrics and Gynaecology, Shaheed Tajuddin Ahmad Medical College Hospital, Gazipur, Bangladesh \\ ${ }^{5}$ Junior Consultant, Department of Obstetrics and Gynaecology, Shaheed Tajuddin Ahmad Medical College Hospital, Gazipur, Bangladesh \\ ${ }^{6}$ Junior Consultant, Department of Obstetrics and Gynaecology, Shaheed Tajuddin Ahmad Medical College Hospital, Gazipur, Bangladesh
}

DOI: $10.36348 /$ sijog.2021.v04i02.005

| Received: 13.02.2021 | Accepted: 24.02.2021 | Published: 28.02.2021

*Corresponding author: Dr. Most Fatima Dolon

\section{Abstract}

Background: Hysterectomy is the removal of the uterus with or without cervix. When this is done through an abdominal incision it is called abdominal hysterectomy. When the approach is through vaginal vault it is called vaginal hysterectomy. Hysterectomy is a major gynecological operative procedure commonly indicated for women with dysfunctional bleeding, uterine leiomyoma, prolapse, endometriosis \& adenomyosis, pelvic pain, premalignant conditions and cancer. Objective: The purpose of the study was to find out the common indications of hysterectomy. Methods: The Study was conducted in the department of obstetrics and gynaecology of Dhaka Medical College Hospital, Dhaka, Bangladesh to find out the common indications of hysterectomy. 100 cases were randomly selected for the study whose common indication of hysterectomy. Clinical examination and evaluation were done from October 2004 to February 2005. Other necessary investigations were done if clinically indicated and to prepare the patient for anesthesia. Statistical analysis of the results was obtained by using window-based computer software devised with Statistical Packages for Social Sciences (SPSS-22). Results: Majority of cases who underwent hysterectomy were 31-40 years $(52 \%)$ of age. Out of 100 cases most of patients (70\%) underwent abdominal hysterectomy and only 30 (30\%) cases underwent vaginal hysterectomy. Out of 33 cases, clinically diagnosed as leiomyoma of the uterus histopathology revealed leiomyoma in 24 cases. In uncomplicated abdominal and vaginal hysterectomy, the duration of surgery was almost same, vaginal hysterectomies needs slightly longer time. Average hospital stay after operation was same. Conclusion: For a woman with severe pelvic pain or heavy irregular periods a hysterectomy often means relief from troublesome symptoms. Hysterectomy is offered as a definitive treatment and is associated with high level of satisfaction. Keywords: Hysterectomy; Abdominal; Gynecological; Premalignant.

Copyright (C) 2021 The Author(s): This is an open-access article distributed under the terms of the Creative Commons Attribution 4.0 International License (CC BY-NC 4.0) which permits unrestricted use, distribution, and reproduction in any medium for non-commercial use provided the original author and source are credited.

\section{INTRODUCTION}

Hysterectomy is a major gynecological operative procedure commonly indicated for women with dysfunctional bleeding, uterine leiomyoma, prolapse, endometriosis \& adenomyosis, pelvic pain, premalignant conditions and cancer [1]. Hysterectomy is the fourth most common operation in the western world, with about 650,000 being performed annually in the USA, of which $70 \%$ are performed abdominally and $30 \%$ by the vaginal route [2]. The vaginal route bas increasingly become the method of choice for hysterectomy. Contraindication for vaginal hysterectomy was usually considered as nulliparity, history of pelvic surgery \& excessive uterine size. These criteria have greatly impeded the use of vaginal route and supported a high frequency of abdominal and laparoscopically assisted hysterectomy in women without prolapse [3]. The improved hospital care, availability of blood transfusion, advanced anesthesia and above all the advent of antibiotics has opened up a new era and thereby broadened the indications for hysterectomy with minimum post-operative morbidity and mortality. However, hysterectomy must never be done without proper indication according to Taylor, hysterectomy should. be done when the risk of 
Most Fatima Dolon et al; Sch Int J Obstet Gynec, Feb. 2021; 4(2): 44-48

preserving the uterus is greater than the risk of removal or when there are disabling symptoms for which there is no successful medical treatment. Vaginal Hysterectomy is advantageous over Abdominal Hysterectomy in removing uteri weighing $\leq 500 \mathrm{gm}$ with comparable operating time, less post-operative pain and shorter recovery. LAVH showed a shorter recovery but longer operating time than $\mathrm{TAH}$ and a $27 \%$ rate of conversion to laparotomy [4].

In our country hysterectomies are performed for more or less similar indication as those performed in advance countries, the only difference being in the evaluation of the patient pre-operatively. We have to diagnose the cases more on the clinical ground rather than modem investigations because of the limited facilities and economical constraint. Even in the clinical assessment there are considerable problems as the patients are mostly illiterate and ignorant. They do not understand the gravidity of their symptoms, often attend the doctor late and cannot explain their problems without leading questions. As a result, the finding often does not correlate with their complaints. The study has been undertaken to find out the common indications of hysterectomy in our country, to detect the patterns of complications and to find out the correlation between clinical diagnosis, preoperative findings and histopathological reports of the 100-case studied.

\section{OBJECTIVE}

The purpose of the study was to find out the common indications of hysterectomy.

\section{METHODS}

The Study was conducted in the department of obstetrics and gynaecology of Dhaka Medical College Hospital, Dhaka, Bangladesh and SSMC and Mitford hospital Dhaka, Bangladesh to find out the common indications of hysterectomy. 100 cases were randomly selected for the study whose common indication of hysterectomy. Clinical examination and evaluation were done from October 2004 to February 2005. Other necessary investigations were done if clinically indicated and to prepare the patient for anesthesia. Then the cases were again evaluated according to preoperative findings. Finally, the specimen was sent for histopathological examination and correlated with clinical and peroperative findings. Statistical analysis of the results was obtained by using window based computer software devised with Statistical Packages for Social Sciences (SPSS-22).

\section{RESULTS}

Majority of cases who underwent hysterectomy were $31-40$ years $(52 \%)$ of age. The total study population was 100 Patients aged 21 years to $\geq 80$ years, $6.0 \%$ were 21 years to 30 years, $52.0 \%$ were 31 years to 40 years, $28.0 \%$ were 41 years to 50 years, $6.0 \%$ were 51 years to 60 years, $5.0 \%$ were 61 years to 70 years and $3.0 \%$ ware $\geq 80$ years. Out of 100 cases most of patients $(70 \%)$ underwent abdominal hysterectomy and only $30(30 \%)$ cases underwent vaginal hysterectomy. Out of 33 cases, clinically diagnosed as leiomyoma of the uterus histopathology revealed leiomyoma in 24 cases. In uncomplicated abdominal and vaginal hysterectomy, the duration of surgery was almost same, vaginal hysterectomies needs slightly longer time. Average hospital stay after operation was same.

Table-I: Demonstrated the distribution of study patients according to age

\begin{tabular}{|l|l|l|}
\hline Age group (years) & $\mathbf{n = 1 0 0}$ & $\mathbf{\%}$ \\
\hline 21 years to 30 years & 6 & 6.0 \\
\hline 31 years to 40 years & 52 & 52.0 \\
\hline 41 years to 50 years & 28 & 28.0 \\
\hline 51 years to 60 years & 6 & 6.0 \\
\hline 61 years to 70 years & 5 & 5.0 \\
\hline$\geq 80$ years & 3 & 3.0 \\
\hline Total & 100 & 100.0 \\
\hline
\end{tabular}

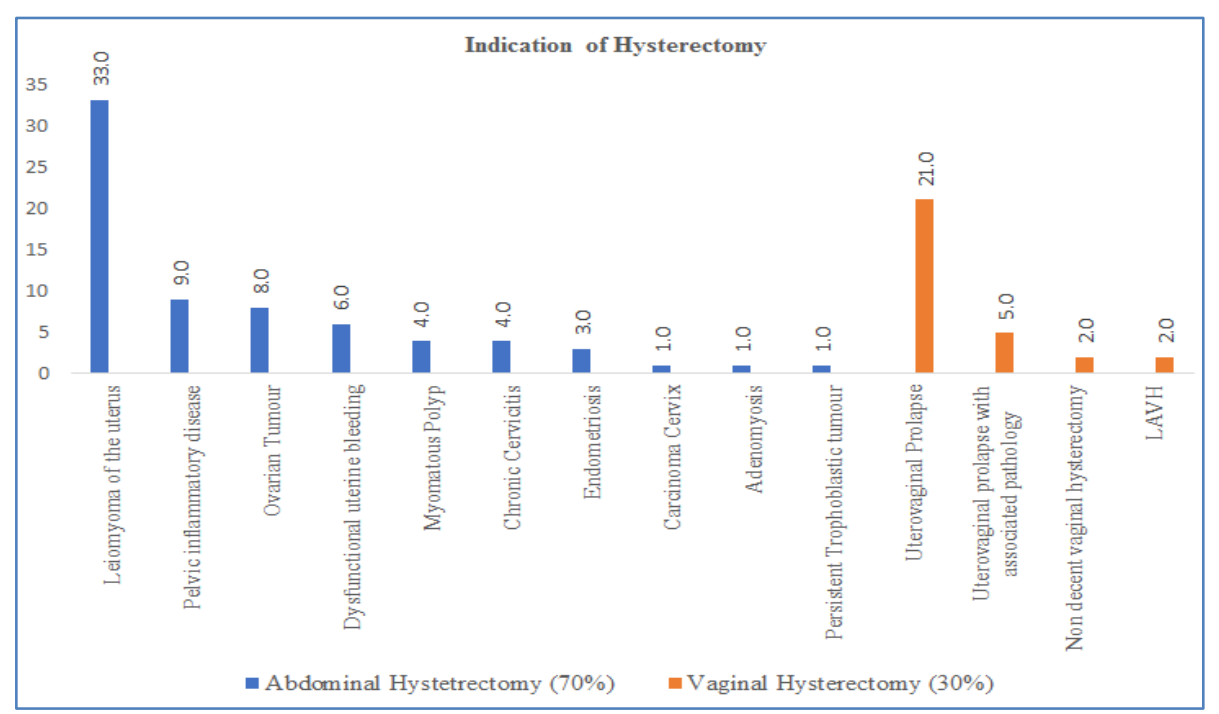

Fig-I: Demonstrated the distribution of study patients according to Indication of Hysterectomy 


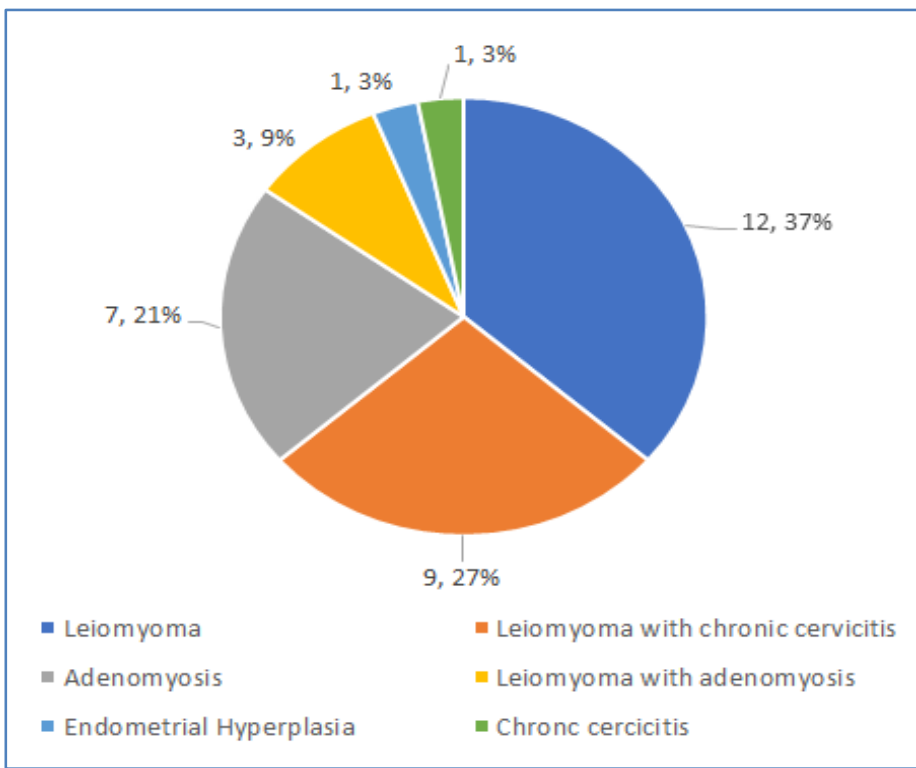

Fig-II: Demonstrated the distribution of study patients according to Final Diagnosis of Histopathology

Table-II: Demonstrated the distribution of study patients according to clinical outcome of abdominal and vaginal hysterectomy

\begin{tabular}{|l|l|l|}
\hline Parameters & TAH & VH \\
\hline Duration of Surgery & $45-75$ Min & $60-90$ Min \\
\hline Post-Operative Hospital Stay & 5 days to 7 days & 5 days to 7 days \\
\hline Types of Anesthesia & $72 \%$ & $24 \%$ \\
\hline GA & $28 \%$ & $76 \%$ \\
\hline Spinal &
\end{tabular}

\section{DISCUSSION}

This study has been performed to find the common indications, complications and morbidity of hysterectomy and to correlate the clinical presentation with the peroperative and hystopathological findings. In the present study, it was observed that maximum number $(80 \%)$ of hysterectomies were done in women between the age of 31 - 50 years. Similar age incidence reported by a1most similar findings were observed in other studies [6-10]. Regarding symptomatology, it was observed that abnormal menstrual flow was the single most common complaints other studies reported hysterectomy due to menstrual disorders [11-15].

Leiomyoma uterus was the most common indication $(33 \%)$ of hysterectomy somewhat similar results were reported other studies [6-10]. Hysterectomy was done for $9 \%$ cases of PID. It showed wide variation in different studies. Rechard C. Dicker 32 showed the incidence of $7.2 \%$ while steven C. white 38 showed incidence of $1.6 \%$ Nancy C 36 showed 5\% and some study showed the incidence $2 \%$. Hysterectomies were done for DUB in $6 \%$ cases. It also showed a wide variation in different studies. In the present series out of $6 \%$ of DUB diagnosed preoperatively, histopathology revealed associated pathology in 5 cases. Only in one case uterus and cervix showed normal architexure on histopathology.
Utero-vaginal prolapse was the indication of vaginal hysterectomy in $26 \%$ cases. In other studies, also observed almost similar findings. According to Shergill et al. 27 Pokras and Hufnaged 37 and was the indication for hysterectomy in $24 \% 20.8 \%$ and $27 \%$ respectively. In $25 \%$ cases of total abdominal hysterectomy bilateral salpingo oophorectomy has been carried out. In $58 \%$ cases both ovaries were preserved. And in $17 \%$ cases of total abdominal hysterectomy one ovary was preserved in women below 45 years having clinically healthy ovaries. In vaginal hysterectomy, ovaries bad been retained after they had been detected normal on sonography but in one case patient had ovarian cyst which could not be removed vaginally and after vaginal hysterectomy laparatomy was done to remove that ovarian cyst. Out of 33 cases of clinically diagnosed leiomyoma was confmned on histopathology in 24 cases. Adenomyosis was found in 7 cases, all of them presented with menorrhagia and associated dysmenorrhoea in every cases uterus was $<12$ wk size[11-17].

Out of 8 cases of ovarian tumour 6cases were clinically diagnosed as benign ovarian tumour and 5 were confirmed as benign ovarian tumour on histopathology. In one case histopathology revealed granulosa cell tumour. 2 cases of clinically diagnosed malignant ovarian tumour were confirmed as malignant on histopathology. So, in most cases pre-operative 
Most Fatima Dolon et al; Sch Int J Obstet Gynec, Feb. 2021; 4(2): 44-48

clinical diagnosis was confirned on histopathological examinati $r$ correlation observed in the study Hysterectomy for endometriosis showed a wide variation in incidence between the different series? Some studys both have shown incidence of $7 \%$ whereas Steven. C. white 38 has shown $1.3 \%$. In the present series only 3 hysterectomies were done for external Endometriosis. The reason for these cases was that preoperatively endometriosis is often not very easy to diagnose clinically.

In the present series 4 hysterectomies had been done for chronic cervicitis. In two cases there were associated PID. In all cases histopathology confirm the diagnosis. But chronic cervicitis was an associated fmdings in 11 cases of leiomyoma of the uterus, 3 cases of DUB, 5 cases of PID 1 cases of endometriosis. In vaginal hysterectomy due to uterovaginal prolapse in all cases cervix showed feature of chronic cervicitis on histopathological examination. Regarding short term outcome vaginal hysterectomy was found to be advantageous in respect of cost of anesthesia and ambulation. Duration of operation was shortening in abdominal hysterectomy and duration of hospital stay was same in the both groups. Various other studies have shown similar outcome[18-20].

Regarding complications febrile morbidity was the commonest $(9 \%)$ complication after hysterectomy followed by urinary tract infection (8\%) Respiratory treat infection (4\%) Similar complication rate was observed by some similar studies Abdominal wound infection was found $6 \%$ in Razia S. series $5 \%$ in Richard C. series $4 \%$ in Dewan F. Series. But in the present series there was no such complication.

\section{CONCLUSIONS}

The indications for hysterectomy in any case must therefore be clearly defined and should be done for which more conservative treatment is not likely to be efficacious. It should be the last resort. In some patient who are incapacitated and distressed by the complains of prolonged bleeding disorder due to functional menorrhagia or myoma, pelvic pain due to endometriosis or pelvic infection etc., hysterectomy is a blessing to them as it removes the diseased organs and all their symptoms are alleviated.

\section{REFERENCES}

1. Consultant, C. O., Lingman, G., \& Ottosen, L. (2000). Three methods for hysterectomy: a randomised, prospective study of short term outcome. BJOG: An International Journal of Obstetrics \& Gynaecology, 107(11), 1380-1385.

2. Sutton, C.J.G. (1999). Laparoscopy and Laparoscopic Surgical Techniques: In Dewhurst's text book of Obstetric and Gynaecology for Post graduates $.6^{\text {th }}$ edition, 60-66.
3. Agostini, A., Bretelle, F., Cravello, L., Maisonneuve, A. S., Roger, V., \& Blanc, B. (2003). Vaginal hysterectomy in nulliparous women without prolapse: a prospective comparative study. BJOG: An International Journal of Obstetrics \& Gynaecology, 110(5), 515-518.

4. Ferrari, M. M., Berlanda, N., Mezzopane, R., Ragusa, G., Cavallo, M., \& Pardi, G. (2000). Identifying the indications for laparoscopically assisted vaginal hysterectomy: a prospective, randomised comparison with abdominal hysterectomy in patients with symptomatic uterine fibroids. BJOG: An International Journal of Obstetrics \& Gynaecology, 107(5), 620-625.

5. Michael, P., Andersion, M.D., FACOG, F.A.C.S., David Chelmow, M.D., Sondra, B. Lee, M.D. Intraoperative and postoperative complications of Gynaecologic Surgery.

6. Razia. S. (2004). Clinicopathological study of hysterectomy in Bangabandhu Sheikh Mujib Medical University, among 100 cases. Dissertation, BCPS, Dhaka.

7. Khastigir, G., studd. J. Oestrogen., \& Osteoporosis. (2002). In studd .J. ed, progress in Obstetric \& gynecology: 14. Edinburgh: Churchill Livingstone.

8. Woodman, N., Read, M.D. (2000). Oophorectomy at hysterectomy. In studd. $\mathbf{J}$.ed. progress in obstestrics and Gynecology Vol- 14 Edinburgh: Churchill livingstone.

9. Jacobs, 1., Hudson, C.N. Jacobs, I. Shepherd, J.H. Oram, D. (2001). eds . $2^{\text {nd }}$.Edition, Ovarian cancer. Oxford: Oxford university press.

10. Magos. A.L., Boornas, N., Sinha, R., Lo, L., Richardson, R.E. (1995). Transvaginal endoscopic oophorectomy. Am. J. Obstet Gyneco1, 1995; 172: 123.

11. Howkins, 1.1Hudsion eN. (2001). Instrument: Operating theatre equipement basic surgical skills. In Shaw's Text Book of operative Gynaecology $6^{\text {th }}$ edition Churchill Livingstone; 63.

12. Dutta, De. (2001). Displacement of the uterus. In text book of Gynecology including contraceptiion. B'" edition. Konar H. calcatta, 205.

13. Shergill, S. K., Shergill, H. K., Gupta, M., \& Kaur, S. (2002). Clinicopathological study of hysterectomies. Journal of the Indian Medical Association, 100(4), 238-9.

14. Edouard, L., \& Rawson, N. S. (1996). Reliability of the recording of hysterectomy in the Saskatchewan health care system. BJOG: An International Journal of Obstetrics \& Gynaecology, 103(9), 891-897.

15. Nahar, L. (1999). Clinical study of abdominal hysterectomy in Sir Salimullah Medical College \& Mitford Hospital, Dhaka. Among 100 cases. (Dissertation ) BCPS, Dhaka.

16. Dewan, F. (1989). Clinical study of 100 cases of abdominal hysterectomy (Dissertation), BCPS, Dhaka. 
17. Amirikia, H., \& Evans, T. N. (1979). Ten-year review of hysterectomies: trends, indications, and risks. American Journal of Obstetrics and Gynecology, 134(4), 431-437.

18. Dicker, R. C., Scally, M. J., Greenspan, J. R., Layde, P. M., Ory, H. W., Maze, J. M., \& Smith, J. C. (1982). Hysterectomy among women of reproductive age: trends in the United States, 19701978. Jama, 248(3), 323-327.

19. Clarke, A., Black, N., Rowe, P., Mott, S., \& Howle, K. (1995). Indications for and outcome of total abdominal hysterectomy for benign disease: a prospective cohort study. BJOG: An International Journal of Obstetrics \& Gynaecology, 102(8), 611620.

20. Sculpher, M. J., Dwyer, N., Byford, S., \& Stirrat, G. M. (1996). Randomised trial comparing hysterectomy and transcervical endometrial resection: effect on health related quality of life and costs two years after surgery. BJOG: An International Journal of Obstetrics \& Gynaecology, 103(2), 142-149. 